\title{
A Review of Electrical Methods as A Worthy Tool for Mineral Exploration
}

\author{
Priscillia Egbelehulu ${ }^{a}$, Abu Mallam ${ }^{a}$, Naeem Abdulsalama ${ }^{a}$, Taiwo Adewumi ${ }^{b}$
}

\author{
${ }^{a}$ Department of Physics, University of Abuja, Abuja. \\ bDepartment of Physics, Federal University Lafia, Nasarawa. \\ Corresponding author email: priscilliaegbelehulu@gmail.com
}

\section{DOI: 10.2478/pjg-2020-0011}

\begin{abstract}
:
This paper focuses on the review of electrical geophysical methods such as electrical resistivity and induced polarization as a technique for mineral exploration. It highlights the general fundamental principles of the electrical methods and result from other investigations. Most rock - forming minerals are insulators, and electrical current is carried through rocks mainly by the passage of ions in pore waters. In light of this, most rocks conduct electricity by electrolytic rather than electronic processes. Since metals and most metallic sulphides conduct electricity efficiently by the flow of electrons, electrical method is efficient and important in environmental investigation especially in areas where metallic objects are the targets and also in the search for sulphide ores. The results from various research showed the applicability of these geophysical ground methods, specially the Induce Polarization method, as a support tool in the identification and selection of exploration targets for test drilling.
\end{abstract}

Keywords: Electrical resistivity, Induced polarization, chargeability, sulphide ores

\subsection{Introduction:}

Applied Geophysics is basically concerned with the investigation of the Earth's crust and near-surface to acquire, most times minerals of economic wealth It covers virtually all areas from determining thickness of the crust (which is of paramount importance in hydrocarbon exploration), to the studies of shallow structures for engineering site investigations, exploring for groundwater and for minerals and other economic resources, it is equally used to locate narrow mine shafts or other forms of buried cavities, or the mapping of archaeological remains, or locating buried pipes and cables - it is most suitable where the total depth of investigation is usually less than $100 \mathrm{~m} \mathrm{[12].}$

The purpose of carrying out these surveys is to investigate the rocks properties associated with mineral of economic value in the survey area. Geophysical methods depend on measuring physical property of rocks. There are only a few of such properties of interest which are - Magnetic Susceptibility, Electrical Conductivity or Resistivity, Radioactivity, Electrical Polarizability, Density, Seismic Velocity [11]. Geophysical survey method can be divided into those that make use of natural fields of the earth and those that require the input into the ground of artificially generated energy. The natural field methods utilize the gravitational, magnetic, electrical and electromagnetic fields of the Earth while the artificial source methods involve the generation of local electrical or electromagnetic fields that may be used analogously to natural field. Generally, natural field methods can provide information on Earth properties to a significant greater depth and are logistically simpler to carry out than artificial source method [9].

Knowing the nature of the mineralization and its origin is a key factor in mining exploration in a given area since minerals are structurally controlled and usually associated with faults, fractures and shear zones. This enables future exploration and gives an idea upon the mining potential of the region [19].

Minerals are often deposited usually beneath the earth surface. Thus detecting them depends largely on the characteristics or properties they possess which differentiate them from the surrounding media. These properties determine the best geophysical method to be adopted in their survey [9].

However, it has been observed that target detection is usually inadequate using a single geophysical method, since identical geophysical anomalies maybe related to an anomaly source with different physical properties, mode of occurrence pattern and nature [3]. Thus, integration of geophysical methods becomes necessary in order to reveal and characterize hidden targets (a typical case is the example of the simultaneous measurement of induced polarization and resistivity data for better interpretation of observed anomalies). The development of integrated studies is more rational than the attempt to improve the precision of separate methods; two (sometimes three) geophysical methods are usually required for the detection of a desired target [10].

This paper attempts to review various electrical method for mineral exploration. Electrical method has been limited to water exploration and in a lot of cases not used for mineral exploration.

Several electrical properties of rocks and minerals are substantial in electrical prospecting. They are natural electrical potentials, electrical conductivity or electrical resistivity which is its reciprocal, and dielectric constant. Of all of these, electrical conductivity stands as the most significant while the rest are considered as minor importance. Electrochemical or chemical activity is usually responsible for some natural or spontaneous potential which occurs in the subsurface. Most rock forming minerals are insulators, and electrical current is carried through rocks mainly by the passage of ions in pore waters. In light of this, most rocks conduct electricity by electrolytic rather than electronic processes. Since metals and most metallic sulphides conduct electricity efficiently by the flow of electrons, electrical method is efficient and important in mineral investigation especially in areas where metallic objects are the targets and also in the search for sulphide ores. Generally, all metals are electrically conductive, but the conductivity of an ore deposit largely depends on sulphides or graphite it lies on [1]. This paper therefore aims at reviewing some electrical methods as applied to mineral exploration.

The objectives of this review is as follows:

- To determine the potency of electrical methods in mineral exploration.

- To reveal why other geophysical methods are preferred to electrical methods in mineral exploration.

- To know the possible limitation of electrical methods in mineral exploration.

This review brings together, the experiences and scientific ideas scattered in several published papers and textbooks that are not readily available to the audience/readership.

\subsection{General Principle}

The Electrical Resistivity of a geologic unit or target is measured in ohmmeters, and depends on its porosity, permeability, water saturation and the concentration of dissolved solids in pore fluids within the subsurface. Electrical Resistivity methods measures the bulk resistivity of the subsurface, so does electromagnetic methods. The major distinction between the two methods is in the way that electrical currents are made or allowed to flow in the earth. In the electrical resistivity method, current is injected into ground through surface electrodes, while in electromagnetic methods, currents are induced by the application of time-varying magnetic fields [16].

The basic principle used in resistivity method is the ohms law (V=IR).

Resistance $\mathrm{R}$, in ohms of a wire is directly proportional to its length $\mathrm{L}$ and is inversely proportional to it cross area $\mathrm{A}$. thus we have that

$R \propto \frac{L}{A} \quad$ Or $\quad R=\frac{\rho L}{A}$

$[15]$ 
Where $\rho$ is the constant of proportionality and is known as electrical resistivity and is a characteristics of the material which is independent of its shape and size [15]. As earlier stated most rock- forming minerals are insulators, thus electrical current is carried through rocks mainly by the passage of ion in pore waters. This means that porosity is the major controlling factor of the resistivity of rocks and resistivity increases as porosity decreases [9].

Archie's Law gives an equation which establishes the relationship between the resistivity of a porous rock and the fluid saturation factor. This law is true for certain types of rocks and sediments, particularly those that have a low clay content. The electrical conduction is assumed to be through the fluids filling the pores of the rock. The relationship between pore-water resistivity $\left(\rho_{w}\right)$ and bulk resistivity $\left(\rho_{o}\right)$ is given by the formation factor (F)

$\mathrm{F}=\frac{\rho_{o}}{\rho_{w}}$

The formation factor is related to porosity $(\varnothing)$ by this equation $\mathrm{F}=\alpha \emptyset^{-\mathrm{m}}$

Where,

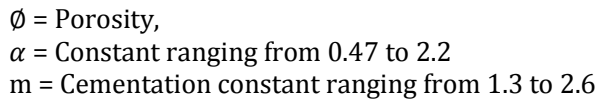

which is the Archie's Law

If scenario is considered where current sink is a finite distance from the source as presented in Figure 1.0. The potential $V_{0}$ at an internal electrode $\mathrm{C}$ which is given by;

$V_{0}=V_{A}+V_{B}$

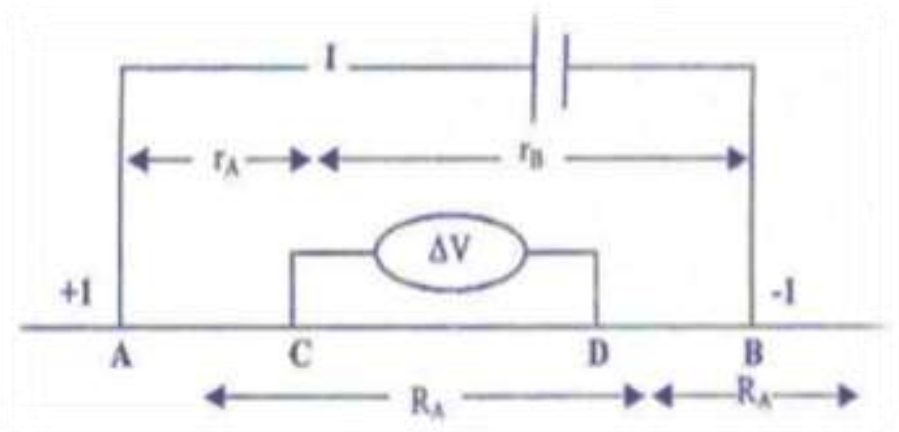

Figure 1: A generalized form of electrode configuration used in resistivity measurements [16].

Absolute potential is usually difficult to monitor in a survey, the potential difference $\Delta V$ between the electrode spacing thus measured as;

$\Delta \mathrm{V}=V_{C}-V_{C}=\frac{\rho I}{2 \pi}\left\{\left(\frac{1}{r_{A}}-\frac{1}{r_{B}}\right)-\left(\frac{1}{R_{A}}-\frac{1}{R_{B}}\right)\right\}$

(Yusuf, 2016)

Therefore;

$\rho=\frac{2 \pi \Delta V}{\left\{\left(\frac{1}{r_{A}}-\frac{1}{r_{B}}\right)-\left(\frac{1}{R_{A}}-\frac{1}{R_{B}}\right)\right\}}$

Where ground is homogeneous, the resistivity from the above equation would be constant independent of either electrode spacing or location. When the subsurface is heterogeneous, the resistivity will vary with relative positions of the electrodes [9]. Computed values are known as the apparent resistivity $\left(\rho_{a}\right)$ which is a function of the inhomogeneity.

$\rho=\frac{2 \pi \Delta V}{\mathrm{I}} K$

$\mathrm{K}$ is the geometric factor, and it is independent of electrode configuration used for any electrical resistivity survey.

\subsection{Electrical Resistivity Method}

Electrical survey is generally used to determine the subsurface resistivity distribution by making measurements on the ground surface. From these measurements, the true resistivity of the subsurface is estimated. Although, the calculated resistivity value is not the "true" resistivity of the subsurface, but rather an "apparent" value which is the resistivity of a homogeneous ground that will give the same resistance value for the same electrode arrangement [14].

Electrical current is injected into the ground through steel electrodes in an attempt to measure the electrical properties of the subsurface. Four metallic electrodes are coupled to the ground and connected to a resistivity meter (terrameter) through conductive wire (figure 2.0). The two outer electrodes A and $\mathrm{B}$ introduce current to the rock formation while the two inner electrodes $\mathrm{M}$ and $\mathrm{N}$ measure the potential difference. However, the measurement of the apparent resistivity of soils and rock is a function of depth or position. The resistivity of soils is a complicated function of porosity, permeability, ionic content of the pore fluids and clay mineralization. Factors which controls the resistivity of earth materials could also include motion of free electrons or ions in the solid, which is occasionally important when dealing with certain kinds of minerals such as graphite, magnetite or pyrite. 


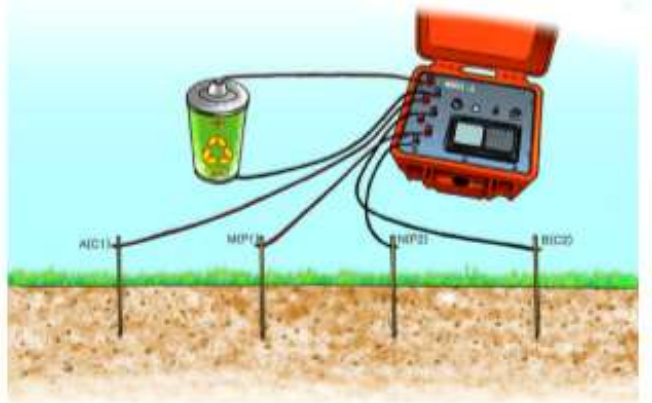

Figure 2: Equipment layout for electrical resistivity survey. (Image extracted from http://www.wtsgeo.com/index.php)

\subsection{Induced Polarization Method}

Induced polarization (IP) helps to alleviate the problem of Converting resistivity to geology since different materials could exhibit similar resistivities by introducing more parameters to distinguish subsurface materials [4].

The induced polarization (IP) geophysical method has been widely used for mineral exploration. This method makes it possible to estimate not only the resistivity distribution but also the chargeability distribution of the subsurface [17]. IP is extensively and effectively used in base metal mineral exploration for locating low-grade ore deposits, e.g., disseminated sulfides. It has other applications in hydro-geophysical surveys, environmental investigations, and geotechnical engineering projects [18]. Measurements of induced polarization are usually made by the convectional electrical resistivity electrode configuration involving two current and two non-polarizable potential electrodes. When the applied current is switch off, the voltage between the potential electrodes takes a finite and measurable time which is several seconds to minutes to decay to zero this occurs because the ground temporarily stores charge (that is) becomes polarized and acts somewhat like a capacitor. However, when the current is turn-on, the voltage does not peak instantaneously but rather builds up over the same time (the rise- time) to its maximum applied value. The voltage decay and rise-time are dependent upon both instrumental and geological factors, and are thus diagnostic of the nature of the ground.

Induced polarization (IP) and resistivity are two electrical properties measured in near-surface sediments as indirect hydrocarbon indicators. They are usually measured at the same time by inserting two electrodes into the earth surface and passing a current through them. After the resistivity measurement is made, the current is shut off and the IP is measured.

\subsection{Review Of Previous Work On The Combined Methods}

Herv-Gouet used direct resistivity (DC) and induced polarization method (IP) to identify gold mineralization channels in Tindikala-Boutou area (Easterncameroon). Geoelectrical surveys were taken along six (06) profiles of $4 \mathrm{~km}$ long in a $100 \mathrm{~m} \times 200 \mathrm{~m}$ grid were made through electrical sounding and profiling using Schlumberger array [6].

Interpretation and analyses of results from the investigation method highlight weak zones or conductive discontinuities to the geologic and tectonic background of the area and mineralized zones. Conductive zones were identified as shear zones within granitic structures of the Precambrian basement, according. The structural trend of these shear zones was E-W. The mineralization within it is N-S and was characterized by high values of chargeability, essentially in the eastern part of the area under study. This mineralization proves the presence of metalliferous or sulphide heaps disseminated in weathered quartz veins which cross shear zones. The poor mineralization and conductive structures in shear zones characterize the groundwater zones. The intense activities of gold washers encountered in the area enable to link that mineralization to gold within quartz veins. The near surface gold mineralization is eluvial or alluvial, and in depth this mineralization is primary.

A study carried out a research on geophysical modeling of manganese deposit using induced polarization method in Itapira Brazil. The Induced Polarization method showed good efficiency in the reconnaissance and morphological characterization of the orebodies in subsurface, mainly due to the presence of disseminated graphite (up to 5\%) in the lateritic/manganese ore and protore, besides the Mn oxides and hydroxides, essentially due to the presence of graphite in the ore, because the polarization of oxides is very low. These results showed the applicability of the geophysical ground methods, specially the IP, as a support tool in the identification and selection of exploration targets for test drilling [8].

Previous study used resistivity and induced polarization to support morphological model of limestone and gneiss deposit of a mining company near the city of Taubaté, Brazil. The research began with a test to verify the accuracy of the geophysical survey method and it was conducted in the same area as a previous drilling campaign with the aim of confirming the possibility of using Vertical Electrical Sounding (VES) and induced polarization (IP) methods, in order to obtain the required information for the deposit morphological modeling. As a result, the application of geophysical methods in the study area reduced up to $75 \%$ the data collection time and presented similar accuracy levels as conventional exploration methods used for the same research objectives [2].

A recent research carried out a research on Orman gold prospect in Mondulkiri province Cambodia. The aim of the research was to develop a new approach in the implementation of the minimum gradient support regularization operator, applied to a time-domain induced polarization problem. The resistivity and induced polarization data were acquired during the geophysical campaign in Mondulkiri Province, Cambodia, on the largest known gold resource of the country. The deposit was an Intrusion Related Gold system, characterized by polarizable sulphides minerals. Four long profiles were realized on the contact zone between a magmatic intrusive and the hosting sediment formations, which is a zone of interest concerning gold mineralization. By implementing different inversion approaches and tuning the focusing parameter, the a-priori information revealed itself as being of uttermost importance on the process convergence towards a stable and realistic solution, and a methodology was therefore established [13].

A study applied electrical resistivity and chargeability data on a GIS platform in delineating auriferous structures in a deeply wethered lateritic terrain Easter Cameroon. Exploration for primary gold in tropical settings is often problematic because of deep weathering and the development of a thick soil cover. The research presented the results of both chargeability and resistivity surveys carried out over the Belikombone hill gold prospect $\left(14^{\circ} 00^{\prime}-14^{\circ} 25^{\prime} \mathrm{E}\right.$ $5^{\circ} 25^{\prime}-6^{\circ} 00^{\prime} \mathrm{N}$ ) in the Betare Oya area (eastern Cameroon), where previous soil sampling had identified gold anomalies. The geophysical data were obtained using Syscal Junior 48 resistivity meter and the Schlumberger configuration array for both the vertical electrical soundings (VES) and horizontal profiling. These data were further built into a GIS framework and the continuity of favorable gold-bearing structures at depth modeled using WINSEV, RED2INV and SURFER extensions software. IP (Induced Polarization)-chargeability and resistivity data combined, identified irregular anomalous zones trending NE-SW The trend was consistent with the attitude of most auriferous quartz veins exposed in artisanal pits and parallel to the regional shear zone system and foliations. The high resistivity anomalies correspond to quartz veins while the relatively high IP anomalies correspond to low sulphide \pm gold concentrations in the quartz veins. Modeling IP-chargeability and resistivity data prepared as contours and 3D maps, culminated to the development of an inferred, irregular and discontinuous mineralized body at depths of up to $95 \mathrm{~m}$. The size and shape of this mineralized body can only later be tested by drilling to ascertain the resource [5]. 
Another research applied geophysical methods to gold prospecting in Loulitou district, Jiadong Peninsula eastern China. The research was based on analyzing previous geological data, some geophysical methods, such as high magnetic measurement, DC resistivity combined profiles, induced polarization (IP) survey, were applied to constrain the distributions of the stratum, structure and magmatic rocks as well as ore-controlling factors in the Loulitou district, Jiaodong Peninsula. The interpretation of surface and underground IP data were used to guide ground prospecting. Through the geophysical methods employed, several possible favorable abnormal locations for concentration of ore-bearing sulfides were distinguished and several locations for gold prospecting were verified by drilling [20].

\subsection{Discussion}

From the work reviewed, electrical resistivity method and induced polarization support morphological modelling of limestone, gneiss, manganese, gold and sulphide mineral deposit. Hence electrical method is a direct method which does not require further investigation and can thus easily detect mineral In areas of problematic setting as a result of deep weathered and thick soil cover electrical and induced polarization data were combined to, identified irregular anomalous zones. The applicability of the geophysical ground methods, specially the IP, serves as a support tool in the identification and selection of exploration targets for test drilling.

There is no ambiguity in its data interpretation unlike the potential field method (magnetic and gravity). The tools for analysis are readily available and cheaper.

The Induced Polarization method showed good efficiency in the reconnaissance and morphological characterization of the orebodies in subsurface. The application of these method as against assumption of time consuming, reduces the data collection time and present similar accuracy levels as conventional exploration methods used for the same research objectives.

\subsection{Conclusion}

most rocks conduct electricity by electrolytic rather than electronic processes. From the literature reviewed, electrical resistivity and induced polarization methods have been successfully combined to investigate metallic mineral deposits. Since metals and most metallic sulphides conduct electricity efficiently by the flow of electrons, electrical method is efficient and important in environmental investigation especially in areas where metallic objects are the targets and also in the search for sulphide ores.

integration of geophysical methods becomes necessary in order to reveal and characterize hidden targets for better interpretation of observed anomalies. The development of integrated studies is more rational than the attempt to improve the precision of separate methods.

\subsection{Acknowledgment}

I thank the anonymous reviewers for all their useful comments and suggestions

\section{References}

[1] M. Airo, "Geophysical signatures of mineral deposit types- synopsis". Geophysical Survey of Finland. Vol. 58 special Paper. 5 - 70. (2015)

[2] C. M Antonio, E. Vagner, T. Giorgio, B.C Jorge, M. Tatiana. "Resistivity and induced polarization to support morphological modeling in limestone mining". Geofisica Internacional. Vol. 55, 227 - 238. 2016

[3] B. Khesin, "Use of geophysical methods for the solution of environmental problems in Isreal”. Hait Journal of Science and Engineering. Vol. 2, 1 - 2. 2005

[4] A.Esben, T. Boesen, C.V. Anders, "A review of airborne electromagnetic methods with focus on geotechnical \& hydrological applications from 2007 to 2017". Advance in Geophysics. Vol. 58, 47 - 93. 2017

[5] V. Fon, V.B. Che, C.E. Suh, "Application of electrical resistivity and chargeability data on a GIS platform in delineating auriferous structures in a deeply weathered lateritic terrain, Easter Cameroon". International Journal of Geoscience. DOI: 10.4236/ijg.2012.325097, Vol. 3, 960 - $971,2012$.

[6] D. Herv-Gouet, T. Ndougsa-Mbarga, A. Meying, S.P. Assembe, Pepogo, "Gold mineralization channels identification in the Tindikala - Boutou Area (Eastern-Cameroon) using geolectrical (DC\&IP) methods: A Case Study". International Journal of Geosciences. http://www.scirp.org/journal/ijg. Vol. $4,643-655.2013$

[8] V.B.Leandro, M.A. Cesar, R.Ariane, Cortes, L.L. George, "Geophysical modeling of the manganese deposit for induced polarization method in Itapira Brazil". Goefisica International. Vol. 55(2), 3 - 10. 2016

[9] P. Kearey, M. Brooks, H. Ian, "An introduction to geophysical exploration”. Third edition, Blackwell Publishing 2002.

[10] J.A. Olowofela, O.0 Ajani, J. Arce, "Inversation methodology for induced polarization method of geophysical Investigation". International Research journal of Geology and Mining. DOI: 10.14303/irjgm.2013.049. Vol. 4(2), 51 - 56, 2014

[11] W.J Scott, “Geophysics for Mineral Exploration” A Manual for Prospectors. Vol. 1- 2, 11-14, 2014.

[12] R.E Sheriff, "Encyclopedic Dictionary of Exploration Geophysics". 4th Edition, Society of Exploration Geophysicists, Oklahoma, USA. Vol. 161.2002.

[13] R. Thiabaut, "Application of Time-Domain Induced Polarization Technique to Characterize the Orman Gold Prospect in Mondulkiri Province, Cambodia". A thesis Submitted to University of Liege, Faculty of Applied Science 2017.

[14] M.H, Loke, "Electrical imaging surveys for environmental and engineering studies", A practical guide to2D and 3D surveys.2001. http://www.geoelectrical.com. 2001

[15] A.A.R Zohdy, "A new method for the automatic interpretation of Schlumberger and Wenner sounding curves geophysics". Vol. 54, 245 - 253, 1989.

[16] T.U Yusuf, "Overview of effective geophysical methods used in the study of environmental pollutions by waste dumpsites". African research review. An international multi-discipline journal Ethopia. DOI: 10.4314/afrrev. v10i2.8. Vol. 10, 134 - 135, 2016.

[17] M.S Zhdanov, "Foundations of geophysical electromagnetic theory and methods". $2^{\text {nd }}$ edition, imprint: Elsevier. 2018

[18] S. K. Haldar, "Mineral exploration 2nd edition", Imprint: Elsevier. 2018.

[19] O.D Olasehinde, G.A Amobi, "Report of Geophysical Investigation Gold Mineralization around Gwagwalada Area”. Nigeria geological survey agency. 2018.

[20] R. Zhang, Y. Meng and S. Sai, "Application of geophysical methods to gold prospecting: An eample from Loulitou district, Jiaoding Peninsula Eastern China". 2016 international conference on computational modeling, simulation and applied mathematics (CMSAM 2016) ISBN:978 - 1 - 60595 - 385 4. 2016. 